\title{
La Monja Alférez, problemáticas \\ de género en el \\ estudio de época
}

Mateo Paganini

Doctorando en Letras de la Facultad

de Filosofía y Humanidades de la

Universidad Nacional de Córdoba

(FFyH-UNC). Proyecto de tesis Doctoral

titulado: "Identidades narrativas en

los márgenes de la América colonial.

Una mirada interdisciplinaria sobre las

autobiografías de Catalina de Erauso y de

fray Servando Teresa de Mier". Dirigido

por Dra. Adriana Rodríguez Pérsico y

codirigido por Dra. Cecilia Inés Luque.

Integrante del Programa de Estudios

Indianos, Centro de Estudios Avanzados

(CEA-UNC). Adscripto al Centro de

Investigación de la Facultad de Filosofía

y Humanidades (CIFFyH-UNC).

Publicaciones: "El riesgo de las letras en

Fedro". In: Cornavaca, Ramón (comp.)

Estudios Platónicos IV [2013]; "FRAY

SERVANDO TERESA DE MIER, una

enigmática personalidad latinoamericana"

[2010].

Contacto: mateopaganini@gmail.com 
PALABRAS CLAVE

Catalina de Erauso; estudios de género; estudios de época; autobiografía; interpretación.

KEY WORDS

Catalina de Erauso; sender studies; studies on ase; autobiography; interpretation.
RESUMEN

El presente artículo aborda las distintas interpretaciones que generó la historia de Catalina de Erauso (1592-1650?), más conocida como la "Monja Alférez", quien escapa de un convento en España y viaja a América vestida de hombre, participando en varias guerras de la Corona española en condición de alférez. Esta historia movilizó diversas interpretaciones, entre las que se pueden reconocer al menos dos tendencias: una, de fines del siglo XIX que tiende a considerarla como un "ser excepcional" o un "fenómeno antropológico", con connotaciones religiosas; otra, corresponde a trabajos de fines del siglo $X X$ y contemporáneos, que enfatizan la identidad sexual ("travesti", "lesbiana", "transexual"). El contraste entre estas interpretaciones abre a la reflexión sobre la importancia de adecuar las categorías analíticas a las particularidades del contexto sociocultural, como así también sobre los riesgos de usar categorías psiquiátricas al considerar este tipo de historias. 
This paper deals with the different interpretations senerated by the particular story of Catalina de Erauso (1592-1650?), better known as the "Lieutenant Nun", who escapes from a convent in Spain and travels to America dressed as a man. She also takes part in several battles as a Lieutenant of the Spanish Crown. This story brings up different interpretations, among which at least two trends can be recosnized: one of them from the late 19th century, in which she is considered "an exceptional being" or an "anthropologic phenomenon", carrying certain religious connotations. The other one, related to the late 20th century and contemporary critical essays, in which, due to the "queer" and "performatividad" theories the view has been renewed. The contrast between the different interpretations opens up new reflections about the importance of sociocultural context and about psychiatric category we usually think of when considering these types of stories. 
“¿Cómo te podrá decir mi lengua, que nací mujer?” Juan Pérez de Montalbán, La Monja Alfére:

"Los viejos hábitos conservan sus raíces en un suelo perturbado por una nueva cultura"

Edward Burnett Tylor, Cultura primitiva.

Por más arraigados que estemos a nuestro hábito, y nos resguardemos en él como la garantía de nuestra identidad, hay ciertos relatos que nos sugieren los modos en que éste puede perderse o abandonarse; lo que hoy se conoce como Historia de la Monja Alférez, relata una vida que se parece mucho a una novela, que exalta constantemente los mecanismos de nuestra credulidad, degradando esa parte sociable que se cimenta en los oficios y las siglas: "El Lic.", "La Dra.", etc. Su paso por América ha generado diversas narraciones y leyendas, sobre todo, el relato de una diversidad insospechada en el siglo XVII. El interrogante abre a la historia: ¿Cómo el hábito de una monja pudo devenir en capa y espada? Dos extremos que parecen irreconciliables, un barco colonial entre dos continentes, la mediación de una vida en fuga por la metamorfosis.

Contar esta historia no carece de complicaciones, porque las formas en que fue llamada, como se llamó y como la llamaron, no coinciden ni descasan bajo un mismo nombre. Fue bautizada como "Catalina de Erauso", transitó por América como "Alonso Díaz Ramírez de Guzmán", pasó a la fama bajo el oxímoron de "Monja Alférez", y finalmente, regresó a América para terminar sus días como "Antonio de Erauso". Por sólo mencionar 
un puñado de los muchos nombres que signaron su vida.

Lo llamativo, es que la perplejidad que provoca la Monja Alférez ha dado lugar a numerosas clasificaciones y diagnósticos en diferentes épocas, desde consideraciones psiquiátricas como las de "hermafroditismo hypospádico" (León, 1923), “travestismo” (Martín, 1994), "lesbianismo” (Velasco, 2000) hasta las tendencias más contemporáneas de considerarla como un fenómeno "transgenérico" (Camacho Platero, 2008). En cierto modo, parece tratarse de un texto que convierte en psiquiatra al lector, como si éste se viera en la necesidad de arriesgar un diagnóstico o una clasificación.

\section{LA INCERTIDUMBRE COMO TEXTO}

Toda clasificación parece complicada. Como si nunca pudiéramos saber hasta qué punto son arbitrarias nuestras diferenciaciones. La problemática de la novela, por ejemplo, a falta de una definición que nos satisfaga, parece haber encontrado una solución de compromiso en la clasificación: novela didáctica, novela de ciencia ficción, novela epistolar, etc. Como si el no saber qué es la novela, encontrara un apaciguamiento en las diferencias de género (saber que una novela didáctica no es una novela de ciencia ficción). Pero a medida que prolifera la literatura, el entrecruzamiento da lugar a inclasificables, rompiendo la precariedad de nuestros esquemas. Este parece ser el caso de la "novela autobiográfica". Por lo general, se suele entender a la novela "como una acción fingida en prosa", pero he aquí que el género de la novela autobiográfica dice ser un relato sobre la propia vida, que pone en juego cierta veracidad del texto exacerbada por su carácter autorreferencial: ¿Quién podría saber su vida más que el propio sujeto que la vivió? El psicoanálisis nos ha advertido sobre la poca fiabilidad de nuestros recuerdos, de que quizás, el relato que hacemos de nuestra propia vida esté al servicio de nuestras inclinaciones narcisistas, de recuerdos encubridores 
y de fantasías; nos ha inculcado cierta sospecha sobre las construcciones que hacemos de nuestro pasado. En la autobiografía la vacilación entre la novela, entendida como algo ficticio, y la supuesta veracidad de la vida, parece no tener tregua. Al punto de ya no saber si la autobiografía es una rama de la literatura fantástica o si debiera pertenecer a la historia como el testimonio fidedigno de una determinada época.

Esta vacilación no aparece sólo en el ámbito de los estudios literarios, la cultura en general ante una falta de respuesta a la pregunta "¿qué es una mujer?" suele responder con la diferencia: qué es una mujer a diferencia del hombre o qué es un hombre a diferencia de la mujer. El género en sus interminables disyunciones, nos cobija en sus casilleros, hasta que surgen piezas imposibles de encasillar haciendo tambalear la estructura precedente. Una de estas piezas, parece ser la autobiografía de Erauso, una vida cargada de acontecimientos fantásticos y, además, la de una mujer que escribe y transita su vida como un hombre. Poniendo en cuestión no sólo al género como diferencia sexual, sino también, abre a preguntas por el género autobiográfico. A tal punto que, quienes se han preocupado por su historia se vieron en la necesidad de adjuntar a su relato testimonios de otras personas, que den fe de su veracidad.

Uno de los ejemplares más antiguos que se conservan de este texto, aparece en los catálogos de la Biblioteca Nacional de Madrid en la sección de "Raros e incunables", otorgándole ya un destino de indeterminación textual que refleja la incertidumbre misma de esta historia. Gran parte de esta incertidumbre se debe al hecho a que todavía no se ha encontrado un documento del cual pueda afirmarse que fue escrito por Erauso, siempre debemos remitirnos a copias que pudieron ser generadas por su propia versión de los hechos, pero esta afirmación queda relegada a un plano hipotético. Justamente el plano hipotético que implica considerarlo como un texto autobiográfico, ha sido el que generó las más diversas interpretaciones sobre esta historia; las cuales se intentará abordar y poner en cuestión. 
Antes de abordar las interpretaciones sobre el texto de Erauso se hacen necesarias algunas puntualizaciones sobre el género autobiográfico. A este respecto, Paul de Man advierte las implicancias que tiene considerar a la autobiografía como un género: "Dado que el concepto de género designa una función estética y una función histórica, lo que está en juego es no sólo la distancia que protege al autor autobiográfico de su experiencia, sino también la posible convergencia de estética e historia" (De Man, 1991, 113). Esta conjunción implicaría equiparar a la autobiografía con los cánones de los géneros literarios mayores, pero a diferencia de estos pareciera no dar garantías de que el acontecimiento estético se produzca, dado que podría tratarse del simple testimonio de un sujeto sin pretensiones literarias. Al decir de Paul de Man, "la autobiografía siempre parece deshonrosa y autocomplaciente de una manera que puede ser sintomática de su incompatibilidad con la dignidad monumental de los valores estéticos" (De Man, 1991, 113). A su vez, su cercanía con la historia, en tanto sea valorada como testimonio, tampoco parece presentar más garantías que la propia palabra del autor (dado que no tendría por qué estar sujeta a una contrastación con documentos históricos). Situación que lleva a Carlos Thiebaut a afirmar que "Nada parece diferenciar y distanciar el texto de una autobiografía "real" de una novela en forma autobiográfica" (Thiebaut, 1990, $20^{1}$ ). La autobiografía como género parece ser un hijo no reconocido por la literatura y una descendencia bastarda o bastardeada por la historia. Sin embargo, a pesar de carecer de un linaje o genealogía disciplinaria, la autobiografía se presenta como un "nuevo rico" de las ciencias humanas, el objeto predilecto de nuevas tendencias que buscan pensar la subjetividad a partir del relato de quien cuenta su vida.

Dentro del contexto de indeterminación genérica de la autobiografía, existe una controversia entre quienes consideran la autobiografía como un género literario que tuvo su origen en el siglo XVIII, en correlato con una visión romántica del hombre occidental y cuyo exponente canónico se 
enconaría en las Confesiones de J. J. Rousseau; y por otra parte, autores como Mijaíl Bajtín quienes afirman que la autobiografía se podría rastrear desde la antigüedad clásica1, en un parentesco cercano con las biografías y los elogios fúnebres, basados en la figura del "encomio" donde prevalecía una retórica pública apologética. La primera perspectiva hace de la autobiografía una empresa de autoconocimiento, la cual llevaría a pensarla como un fenómeno casi poscolonial en América y a considerar que las Relaciones, las Crónicas y las Probanzas de Méritos, por ejemplo, si bien podrían estar escritas en primera persona, no hubieran alcanzado esa finalidad gnoseológica; mientras que en la segunda perspectiva, no parece tratarse de una empresa de conocimiento desinteresada del yo que busca reconstruir su tiempo pasado, sino que se presenta como la escena de una polémica con sus contemporáneos, y nos alerta sobre el contexto político en que surgieron estos relatos.

En consonancia con esta segunda perspectiva, la Historia de la Monja Alférez ha sido pensada por muchos autores como un texto autobiográfico cuya finalidad era la de una probanza de méritos ante la Corona española. Idea que no resulta descabellada, al mostrar éste varias hazañas que realizó Erauso en condición de soldado de la Corona; sin embargo, no se reduce a un itinerario de proezas, sino que relata acontecimientos de su vida personal que parecen exceder a sus méritos. Una hipótesis más osada y precisa, es la que expresa Gema Areta Marigó, al decir que "el auténtico origen del relato de Catalina de Erauso reside en la exposición autobiográfica [...] verdadero origen novelesco de una escritura que intenta esclarecer y de-

1 Mijaíl Bajtín en Teoría y estética de la novela, rastrea la autobiografía en la antigüedad clásica y reconoce a su primer exponente en el discurso de Isócrates: "Basada en los esquemas biográficos del encomio, apareció la primera autobiografía en forma de discurso en defensa propia; la autobiografía de Isócrates, que tuvo una enorme influencia sobre toda la literatura universal (especialmente, a través de los humanistas italianos e ingleses). Se trata de un informe apologético público de su vida” (Bajtín, 1989, 289). 
terminar su propia leyenda" (Areta Marigó, 1999, 244-5). La hipótesis de Areta Marigó pareciera confirmarse por el hecho de que en el texto mismo aparecen referencias de Erauso a su propia leyenda: "Entramos en Lima ya de noche, y sin embargo ya no podíamos valernos de tanta gente curiosa que venía a ver a la Monja Alférez" (Erauso, 2002, 163). Esta idea muestra lo excepcional de la situación: por lo general, se suele escribir una autobiografía para procurarse una leyenda, aunque sea modesta; pero en este texto tendríamos el caso inverso, alguien que escribe su vida para esclarecer su propia leyenda, inscribiendo este relato entre "las grandes personalidades de la historia", que luego de haber alcanzado la fama y el prestigio, relatan su vida destacando desde la infancia los augurios que insinuaban el gran destino que les esperaba. Una lectura de la propia vida a posteriori que suele generar esta idea de un plan prestablecido. Sin embargo en el texto, a pesar de haber sido criada en un convento, no aparece ninguna participación de una providencia divina, que la incite a cambiar su hábito monástico por la capa y la espada, ni tampoco alguna sugerencia patriótica que la impulse a viajar a América; sino que su historia comienza relatando una fuga. Quizás el impulso a huir, sea uno de los movimientos más propios e internos, muy distinto a los impulsos de otras historias legendarias, como las voces que interpelaban a Juana de Arco; se hace difícil imaginar una voz que interpele al sujeto, desde el exterior, diciéndole: ¡Huye! (lo cual sacaría el carácter heroico a la historia). En este relato, se comienza por la fuga del convento, luego de una riña de Erauso con una monja mayor: "era robusta, y yo muchacha; me maltrató de manos, y yo lo sentî” (Erauso, 2002, 94). La ofensa parece precipitar la decisión de abandonar el convento, una noche en víspera de San José, aprovecha la distracción de la congregación en los maitines, para huir: 
y hilo, y una aguja; tomé unos reales de a ocho que allí estaban, tomé las llaves del convento y salí, y fui abriendo puertas y emparejándolas, y en la última, que fue la de la calle, dejé mi escapulario y me salí a la calle sin haberla visto ni saber por dónde echar ni adónde ir. Tiré no sé por dónde, y fui a dar en un castañar que está fuera, y cerca a las espaldas del convento, y acogíme allí; y estuve tres días trazando y acomodándome y cortando de vestir. Corté e híceme de una basquiña de paño azul con que me hallaba, unos calzones; de un faldellín verde de perpetuán que traía debajo, una ropilla y polainas: el hábito me lo dejé por allí, por no ver qué hacer con él. Cortéme el cabello y echélo por ahí, y partí la tercera noche y eché no sé por dónde, y fui calando caminos y pasando lugares por me alejar, y vine a dar a Vitoria, que dista de San Sebastián cerca de veinte leguas, a pie, y cansada, y sin haber comido más que yerbas que topaba por el camino. (Erauso, 2002, 95)

Esta escena parece repetirse varias veces en el relato de su vida, ya sea como criado de un hidalgo, como marinero de un navío o como alférez del ejército; luego de algún conflicto con otro, suele emprender la fuga y recomenzar su identidad, con un nombre adecuado a la nueva situación. El nombre que elige luego de esta transformación cosmética es el de "Francisco Loyola" (Erauso, 2002, 96), y el hecho de que siempre, salvo una excepción, optara por identidades masculinas, fue lo que más llamó la atención de esta historia; generando cierto vértigo diagnóstico entre las interpretaciones actuales sobre este relato. Situación que nos vincula al género, no sólo en lo que respecta al género autobiográfico, sino entendido como diferencia sexual. 


\section{LA PRECIPITACIÓN DIAGNÓSTICA}

Se hace notorio que muchos de los artículos que se han escrito contemporáneamente sobre Catalina de Erauso, ya desde su título apelan a clasificaciones psiquiátricas: "Desnudo de un travesti, o la 'autobiografía" de Catalina de Erauso" (Martín, 1992); "El poder del cuerpo y sus gestos; travestismo e identidad de género en América Colonial: El caso de Catalina de Erauso" (Rocha, 2003); "Travestismo, lesbianismo e identidad transgenética de Catalina de Erauso, la Monja Alférez" (Camacho Platero, 2008); y en otros artículos que si bien no presentan los términos "travesti”, "lesbianismo", "transexualidad", en el título, éstos no tardan en aparecer en el texto, y a lo largo del mismo se toma una determinación por alguna de estas categorías.

La propuesta de Chole Rutter-Jensen en su artículo "La transformación trasatlántica de la monja alférez” (2007) expresa una tesis sugerente: "Erauso logra un cambio de sexo a través de una operación narrativa" (Rutter-Jensen, 2007, 87). Para llegar a la misma se apoya en la teoría sobre la narrativa transexual de Jay Posser (1998), quien formula el síndrome de haber nacido en el cuerpo equivocado, basándose en testimonios y autobiografías de personas que en el siglo XX han cambiado su genitalidad mediante la cirugía.

Parece acertada la tentativa de Chole Rutter-Jensen de comparar el relato de Catalina de Erauso con las narrativas caballerescas y picarescas, sobre todo por ser modelos literarios contemporáneos a Erauso, que le pueden haber servido de modelo para narrar su vida. Sin embargo, Rutter-Jensen parece abusar del término transexualidad, no sólo por el desfasaje temporal que implica pensar un personaje de la modernidad temprana con categorías posmodernas - problemática que la autora misma advierte en su artículo - sino, que a su vez, el texto carece de cualquier tipo de referencia a un equívoco de la naturaleza al modo de: "un hombre en el cuerpo de 
una mujer"; e incluso, hay una completa ausencia de Dios en la determinación genérica de Erauso, no aparece ningún mensaje divino que promueva el cambio de sexo o el vestirse de hombre, como podría encontrarse en una hagiografía. El texto muestra una mujer que se viste de hombre y que prueba su hombría en numerosas hazañas, esta condición, da lugar a un continuo coqueteo con el otro, en que prima el equívoco; las fugas de Erauso son determinadas, en algunas ocasiones, por las propuestas matrimoniales, ante el lecho nupcial, donde su hombría corre el riesgo de perder su velo. El velo parece de vital importancia en esta historia, por lo que la suposición - de que ya era transexual y de que si su época hubiera poseído los medios tecnológicos actuales se hubiera operado - resulta totalmente desmedida. Rutter-Jensen no incurre en tal conjetura, pero en su comparación con la narrativa transexual del siglo XX, termina por decir algo similar: "Como la narrativa precede a la operación; o, en el caso de Erauso, la legitimidad, el sujeto es ya transexual aunque puede no ser reconocido como tal" (Rutter-Jensen, 2007, 94).

Parece bastante contradictorio que estas nuevas lecturas, que han enfatizado sobre la construcción social e histórica del género, apelen a términos como "transexualidad" a la hora de pensar un caso del siglo XVII, cuando todavía estas nociones no existían. Por una parte, pareciera incurrirse en un anacronismo desmedido al pensar a la Monja Alférez como el primer transexual de América, pero por otra, podríamos caer en un hermetismo, que clausure en "aquella época" la significación del texto, convirtiendo a la Monja Alférez en una ruina inaccesible para nosotros. Quizás uno de los privilegios que nos proporciona nuestro tiempo, sea el de tener acceso a las distintas interpretaciones de las que ha sido objeto este texto, la posibilidad de apropiarnos de la distancia que nos separa de él, poniendo en cuestión las interpretaciones de distintas épocas.

Sobre esta problemática del tiempo y su interpretación, nos advierte Mijaíl Bajtín al decir: "Ni Shakespeare mismo, ni sus contemporáneos, co- 
nocieron al "gran Shakespeare" que conocemos ahora. Es absolutamente imposible hacer caber nuestro Shakespeare en la época isabelina" (Bajtín, 2008, 346); o de un modo más jocoso, mediante el chiste escolar "los griegos antiguos no sabían de sí mismos lo más importante: no sabían que eran antiguos griegos, y nunca se denominaron asî" (Bajtín, 2008, 348)2. Por este motivo, propone el abordaje de los personajes históricos por medio de lo que llama extraposición, la cual no implicaría un olvido de la época a la que pertenece el investigador y un intento de traslado a la época en que está situado el personaje estudiado, sino una conservación de la distancia que permita el diálogo entre diferentes épocas.

Desde esta perspectiva, puede observarse que los escritos sobre Erauso de fines del siglo XIX y principios del siglo XX, apuntan a lo inclasificable y a lo singular del caso, como Antonio Sánchez Moguel que menciona a Erauso como un "fenómeno antropológico" (Sánchez Moguel, 1982, 6), Thomas de Quincey destaca lo excepcional de su historia y Pedro Grenón que refiere a Erauso como un "singular personaje" (Grenón, 19--?, 6), manteniendo una ferviente apología del caso, en la que prefiere destacar todo lo que no es: "Ni menos es un aborto psíquico de la humanidad o caso patológico del sentir común" (Grenón, 19--?, 24), a arriesgar un diagnóstico. Por lo general, en estos escritos, se suele destacar el carácter religioso que le otorgaba el primer término de la conjunción "Monja Alférez", así como su castidad, en cierto modo se tiende a pensarla como un ser asexuado; mientras que en los artículos contemporáneos se enfatiza sobre la sexualidad y se especula con sus posibles relaciones lésbicas.

Podrían distinguirse así dos hermenéuticas o interpretaciones sobre esta historia. Una que corresponde a los escritos del siglo XIX y principios del $\mathrm{XX}$, en la que se destaca la singularidad, la excepcionalidad, lo asexuado y 
el carácter religioso; otra, que corresponde a los artículos de fines del siglo XX y principios del XXI, donde se busca alguna clasificación entre las entidades clínicas, se resalta la sexualidad en desmedro del carácter religioso.

Otro aspecto que parece diferenciar entre las dos hermenéuticas mencionadas, es la preocupación de los autores del siglo XIX por la autenticidad del texto, mientras que en la actualidad se evade esta problemática. Joaquín María Ferrer, editor del libro Historia de la monja alférez, doña Catalina de Erauso, escrita por ella misma en 1829, escribe un extenso prólogo donde cuenta su relación con el manuscrito, desde que este llegó a sus manos y le pareció meramente una ficción, hasta que luego de contrastarlo con varios documentos históricos se convenció de que no se trata de un ente imaginario. En la novela de Thomas de Quincey, también aparece una inquietud constante por la veracidad de la historia; y Antonio Sánchez Moguel opta por considerar a Catalina de Erauso como un ser histórico real, pero al texto editado por Ferrer como una versión apócrifa. Los trabajos actuales dan por sentado de que el texto que se conoce pertenece a Erauso, e incluso, ni si quiera sospechan, de que perteneciéndole se dé la posibilidad de fabular la propia vida; pero al pasar por alto esta problemática, se pierde una cualidad que parece constitutiva de esta historia, la dinámica del velo, que al esconder y mostrar ante el otro, va generando pliegues al relato.

Entre la singularidad que había destacado el siglo XIX y la particularidad que se busca actualmente, dentro del espectro de origen psiquiátrico: travesti, transexual, etc. aparece otra interpretación, que curiosamente es contemporánea a Erauso, la de Juan Pérez de Montalbán, quien escribe una comedia histórica que titula La Monja Alférez. [1626?]; la cual expresa cierta conciencia del extrañamiento de su tiempo ante la situación, al decir: "Ser una mujer soldado, y una Monja Alférez es, el prodigio más extraño, que en estos tiempos se ha visto" (Pérez de Montalbán, 1908, 257). Esta perplejidad aparece también en boca del protagonista, Guzmán (uno de los sobrenombres masculinos que utilizó Erauso), al preguntar, luego de 
un largo monólogo: "¿cómo te podrá decir mi lengua, que nací mujer?" (Pérez de Montalbán, 1908, 225). La ausencia de palabras que den cuenta de este suceso, parece mostrar una grieta del lenguaje, que posteriormente intentaron suturar con los términos psiquiátricos.

\section{LAS PERMANENTES FUGAS DE ERAUSO}

Como se ha podido apreciar en este pequeño recorrido, la historia de Catalina de Erauso siempre ha generado cierto revuelo en torno a la consideración de su legitimidad, parece haber despertado la inquietud, en lectores de distintas épocas, de hasta qué punto una historia así fue posible, qué de cierto posee el texto que hoy se conoce como propio de su autoría.

En lo que respecta al texto, excede a un simple itinerario destinado a probar sus méritos como alférez de la Corona española, narra algunas circunstancias de su vida que parecieran insinuar al lector el modo en que Erauso ha llegado a ser quien es; desde su nacimiento hasta los múltiples desencuentros que vivió como monja, criado, marinero y alférez. Ninguno de estos oficios parecía un lugar cómodo y definitivo, sino que siendo su inclinación la de "andar y ver el mundo" (Erauso, 2002, 110), transitó por diversos espacios y roles sociales. Algo de esta historia sigue resultando increíble, los esfuerzos de Joaquín María Ferrer de contrastar el manuscrito con documentos históricos parecen no haber bastado para acallar la sensación de lo extraordinario en los lectores.

Otros relatos de vida, vinculados a los primeros viajes de América, no han provocado tanta suspicacia en sus receptores, y quizás lo que más escandaliza la verosimilitud de esta historia, sea que la frontera de la diferencia sexual pueda ser atravesada en un cambio de atuendo. Que el velo sea lo que permite la transgresión de la diferencia. Aunque también acompañan esta historia los testimonios de las proezas militares de Erauso, las cuales, hasta el momento, parecían patrimonio exclusivo de la hombría. No se 
trataría sólo de vestirse como un hombre, sino de actuar como un hombre hasta en el escenario de la guerra. Burlando así la supuesta esencia de la hombría, en el espacio público de las hazañas militares. La esencia remplazada por la escénica, trasgrede los mecanismos de nuestra credulidad; y no parece casual que en aquel tiempo, esta trasgresión haya encontrado su lugar en el teatro de Pérez de Montalbán, quien dio a la publicidad esta historia con su comedia La Monja Alférez:

Si nos limitáramos a decir que Erauso fue un transexual que su tiempo no supo reconocer como tal, caeríamos en la ilusión de creer que las categorías de nuestro tiempo siempre existieron sólo que todavía no habían sido nombradas; pero, además, perderíamos en la visión actual sobre la época colonial, quizás lo más significativo de esta figura, la conjunción a la que da lugar la Monja Alférez: la unión del hábito monástico y la espada, verdadera alegoría de la colonización española, una monja que impone la cristiandad a espadazos en América.

La monja de la espada es una figura que aparece cuando ya la historia ha dejado caer varios de sus velos, e incluso parece tratarse de un oxímoron que Erauso se niega a reconocer como propio. Aparece como una denominación exterior, que viene de los otros, un apodo o sobrenombre, los cuales siempre rozan entre lo ofensivo y alguna característica muy visible a los otros, mostrando un espejo donde el sujeto no siempre está dispuesto a verse; muy distinto a los seudónimos que Erauso utiliza deliberadamente ante los otros: "Francisco Loyola" o "Alonso Díaz Ramírez de Guzmán”.

Quienes han tratado de clausurar la significación de esta historia mediante algún veredicto diagnóstico, haciendo de Erauso una espacie de "adelantado a su época” que ya era transexual, sólo que su tiempo no sabía reconocerlo como tal; han perdido en el espectro del prefijo "trans", el toque de travesura y de burla a los oficios que implica el relato, el permanente juego con el velo y la fuga, la escena carnavalesca y un poco hostil, que expresa el texto en sus últimas líneas: 
En Nápoles, un día, paseándome en el muelle, reparé en las risotadas de dos damiselas que parlaban con dos mozos. Me miraban, y mirándolas, me dijo una: "Señora Catalina, ¿adónde se camina?" Respondí: "Señoras putas, a darles a ustedes cien pescozones y cien cuchilladas a quien las quiera defender." Callaron y se fueron de allí. (Erauso, 2002, 86)

Las risas que se describen muestran este entorno ofensivo de extrañamiento ante Erauso, su respuesta redobla la hostilidad al cuestionar el lugar de la mujer y provoca el silencio en quienes querían mofarse. Si bien la burlona y rimada pregunta "Señora Catalina, cadónde se camina?" clausura la incertidumbre de género al otorgarle un lugar fijo: el de señora; deja el interrogante abierto sobre la errancia. Quizás este entorno hostil fue el que inspiró esa vocación de trotamundos y las múltiples fugas de Erauso, que todavía hoy son una herida en los catálogos, y que seguramente, seguirán produciendo nuevas clasificaciones e interpretaciones.

Valdría la pena recordar que la palabra "categoría” en su raíz etimológica proviene del griego katēgoreín (acusar); en este sentido, la Historia de la Monja Alférez es una apología ante las clasificaciones con que se buscó encasillar a Erauso. El relato de esta vida carece de cualquier búsqueda personal de autoconocimiento o de cualquier tipo de determinación por una identidad fija, más bien, muestra los modos en que la fuga y el velo le permitió transitar la colonia. La figura de la Monja Alférez que se va delineando a lo largo del relato carecería absolutamente de sentido sin su trasfondo colonial. 


\section{REFERENCIAS BIBLIOGRÁFICAS}

Areta Marigó, Gema. "El barroco y sus máscaras: Vida y sucesos de la Monja Alférez”. In: Anuario de Estudios Americanos, vol. 56, No 1, 1999, 241-252.

Bajtín, Mijaíl. Teoría y estética de la novela: trabajo de investigación. Madrid: Taurus, 1989. . Estética de la creación verbal. Buenos Aires: Siglo XXI, 2008.

Camacho Platero, Luzmila. "Travestismo, lesbianismo e identidad transgenética de Catalina de Erauso, La Monja Alférez”. In: Destiempos14, 2008, 585-593.

De Man, Paul. "La autobiografía como desfiguración”. In: La autobiografía y sus problemas teóricos. Estudios e investigación documental. Anthropos Suplementos29, 1991, 113-118.

De Quincey, Thomas. La Monja Alférez. Valencia: Pre-Textos, 2002.

Erauso, Catalina de. Historia de la Monja Alférez (doña Catalina de Erauso) escrita por ella misma e ilustrada con notas y documentos por Joaquín María Ferrer. Madrid: El sol, 1918.

- Historia de la monja alférez, Catalina de Erauso, escrita por ella misma. Madrid: Cátedra, 2002.

Grenón, Pedro. La Monja Alférez: Doña Catalina de Erauso, 1592-1635. Córdoba, Biffignandi, 19--?. 
León, Nicolás. "La Monja Alférez, Doña Catalina de Erauso ¿Cuál era su verdadero sexo? Estudio psico-médico”. In: Anales del Museo Nacional de Arqueología, Historia y Etnografía, 4 época, t. 2, 1923, 257-287.

Martín, Adrienne L. 'Desnudo de un travesti, o la 'autobiografía' de Catalina de Erauso". In: Juan Villegas (ed.), Actas Irvine-92, Asociación Internacional de Hispanistas II, La mujery su representación en las literaturas Hispánicas, 1992, 34-41.

Pérez de Montalbán, Juan. "La Monja Alférez, comedia famosa de Juan Pérez de Montalbán”. In: Fitzmaurice-Kelly, James (org.) The Nun Ensign, translated from the Spanish with an Introduction and Notes by James Fitzmaurice-Kelly. Londres: T. F. Unwin, 1908, 145-287.

Rocha, Víctor. "El poder del cuerpo y sus gestos; travestismo e identidad de género en América Colonial: El caso de Catalina de Erauso". In: Revista digital Cyber Humanitatis, No 27, 2003. <http://www.cyberhumanitatis.uchile.cl/index. php/RCH/article/viewArticle/5687/5555.> Acesso em: 24 de abril de 2015.

Rutter-Jensen, Chloe. "La transformación transatlántica de la monja alférez". In: Estudio Sociales28, 2007, 86-95.

Sánchez Moguel, Antonio. "El alférez doña Catalina de Erauso". In: La Ilustración Española y Americana, tomo XXXVI, 1892, 6-7.

Thiebaut, Carlos. Historia del nombrar. Dos episodios de la subjetividad. Madrid: Visor, 1990.

Tylor, Edward Burnett). Cultura primitiva. Madrid: Ayuso, 1977.

Velasco, Serry. The Lieutenant Nun: Transgenderism, Lesbian Desire, and Catalina de Erauso. Austín: University of Texas Press, 2000. 